\title{
Targeted temperature management in neurocritical care: Boon or bust
}

\author{
Ashish Bindra, Deepak Gupta ${ }^{1}$
}

\begin{abstract}
Temperature management in neurocritical care is important and has gained due importance in recent years. Targeted temperature management (TTM) includes deliberate reduction of core body temperature to a range of $32-34^{\circ} \mathrm{C}$ in comatose survivors of cardiac arrest after return of spontaneous circulation and also therapeutic hypothermia $\left(33-35^{\circ} \mathrm{C}\right)$ in normothermic patients or controlled normothermia (cooling patients to $37^{\circ} \mathrm{C}$ ) in hyperthermic patients. This review focuses on the practical aspects of cooling and temperature management in neurocritical care. An electronic search of Google Scholar, MEDLINE (OVID), EMBASE and the Cochrane library was performed. The physiological changes, potential side effects along with significant research and clinical applications in the field of temperature management are main highlights. Currently, the research evidence is available for TTM in adults following cardiac arrest, neonatal hypoxic ischaemic encephalopathy and raised intracranial pressure. Controlled normothermia in neurocritical care population is rapidly gaining popularity. However, data on disease specific therapeutic markers, therapeutic depth and duration and prognostication of this modality are limited. Overall in experienced hands, the technique is safe to execute without the major morbidity and a potential to improve the outcome. Though over the years, clinical applications are unable to consistently demonstrate its benefits, but TTM in neurological insult has become an established and promising concept.
\end{abstract}

Key words: Adverse effects, controlled normothermia, cooling, indications, targeted temperature management, therapeutic hypothermia

\section{INTRODUCTION}

The global burden of neurological injury is gigantic. The constant need to improve outcome following the neurological insults has given birth to desperate yearning for cerebroprotective agents. Though the magic pill for the same is missing, but a range of agents with the assorted mechanism of action are being tested. By virtue

Departments of Neuroanesthesiology and ${ }^{1}$ Neurosurgery, All India Institute of Medical Sciences and Associated Jai Prakash Narain Apex Trauma Centre, New Delhi, India

Address for correspondence:

Dr. Ashish Bindra, All India Institute of Medical Sciences and Associated Jai Prakash Narain Apex Trauma Centre, New Delhi - 110 029, India.

E-mail: dr_ashi2208@yahoo.com

\begin{tabular}{|l|l|}
\hline \multicolumn{2}{|c|}{ Access this article online } \\
\hline Quick Response Code: & Website: \\
\hline & www.jnaccjournal.org \\
\cline { 2 - 3 } & \\
\hline
\end{tabular}

of its versatile mechanism of action, hypothermia (HT) has been looked upon as one of the most eligible contenders among these agents. Its foundation is based on the rich history of experimental and clinical research. It has fascinated the mankind by anecdotal reports of remarkable neurological recovery despite prolonged resuscitation in victims of near-drowning in ice-cold water. $^{[1]}$ Targeted temperature management (TTM) after neurological insult is now a well-established and enticing concept. This review focuses on the practical aspects of cooling and temperature management in neurocritical care. The physiological changes, potential side effects along with significant research and clinical applications in the field of temperature management are main highlights. An electronic search of Google scholar, MEDLINE (OVID), EMBASE and the Cochrane library

This is an open access article distributed under the terms of the Creative Commons Attribution-NonCommercial-ShareAlike 3.0 License, which allows others to remix, tweak, and build upon the work non-commercially, as long as the author is credited and the new creations are licensed under the identical terms.

For reprints contact: reprints@medknow.com

How to cite this article: Bindra A, Gupta D. Targeted temperature management in neurocritical care: Boon or bust. J Neuroanaesthesiol Crit Care 2016;3:96-109. 
was performed. The search terms used included ' $\mathrm{HT}^{\prime}$, 'cooling' or targeted temperature management in various combinations with 'methods', 'devices', 'induction', 'indications', 'arrhythmias', 'haemodynamic', 'bleeding', 'side effects', 'coagulopathy', 'infection', 'immune suppression' and various others were used.

\section{Physiology of temperature regulation}

The human body is roughly divided into two thermal compartments: A 'core' compartment consisting of the trunk and head and a 'peripheral' compartment consisting of the skin and extremities. Under normal physiological conditions, core body temperature (CBT) is strictly regulated around a set point of $36.6^{\circ} \mathrm{C} \pm 0.38^{\circ} \mathrm{C}$. The temperature of the peripheral compartment is less strictly controlled and under normal circumstances is $2-4^{\circ} \mathrm{C}$ lower than the core temperature. The brain temperature is slightly higher than the CBT. The mean gradient ranges from $0.3^{\circ} \mathrm{C}$ to $1.1^{\circ} \mathrm{C}$. This difference may increase to $2-4^{\circ} \mathrm{C}$ during fever and other events of neurological insults. Conversely, it may disappear or reverse in cases with an abrupt rise in systemic temperature or suppression of cerebral activity..$^{[2,3]}$ There is a spatial variation in temperature within the brain itself. Deeper and areas with higher metabolic activity have a higher temperature. High brain temperature following neurological insult has a deleterious effect and potentiates excitotoxic brain injury.

CBT is measured from core body sites such as the oesophagus, pulmonary artery, nasopharynx or tympanic membrane or intermediate sites such as oral (sublingual), rectal or bladder. Peripheral temperature measurements are obtained from forehead skin or axilla. CBT is less affected by vasomotor or thermoregulatory mechanisms. Temperature measurement site must be chosen according to need and feasibility. Brain temperature cannot be predicted accurately from CBT. It can be measured in brain parenchyma (sensor coupled with brain tissue oxygen sensors or intracranial pressure [ICP] probes), cerebral ventricle or in the subdural space. Measuring brain temperature is complex and invasive that is why even during aggressive HT therapies it's often guessed from CBT only. Brain temperature was not measured even in the most important studies of HT after cardiac arrest and perinatal asphyxia. Many non-invasive devices to measure brain temperature are being developed, but none is widely available for clinical use. Though brain temperature is the therapeutic target, but CBT continues to be used as a surrogate.

\section{DEFINITION}

HT is defined as $\mathrm{CBT}<36^{\circ} \mathrm{C}$ while fever is $\mathrm{CBT}>38^{\circ} \mathrm{C}$. Deliberately inducing HT is often referred to as therapeutic HT (TH) or induced HT (IH). Accidental HT is an involuntary drop in $\mathrm{CBT}<35^{\circ} \mathrm{C}$. TH is broadly divided into mild HT (CBT $35.9-34.0^{\circ} \mathrm{C}$ ), moderate HT (CBT $\left.33.9-32.0^{\circ} \mathrm{C}\right)$, moderate deep HT $\left(\right.$ CBT $\left.31.9-30.0^{\circ} \mathrm{C}\right)$ and deep HT $\left(\mathrm{CBT}<30.0^{\circ} \mathrm{C}\right) .{ }^{[4]}$ Previously, the hypothermic neuroprotection was thought to be solely due to temperature dependent reduction in metabolism; lower the temperature, greater the protection consequently deep HT were practised. The associated complication burden was huge. Over the years, other mechanism of action of HT became known and mild to moderate temperature drop gained popularity. It had a low incidence of unfavourable effects. The recommended temperature range of $32-34^{\circ} \mathrm{C}$ is widely used clinically and has been extrapolated from animal experiments. ${ }^{[5]}$ The term targeted temperature management (TTM) was coined to refer to deliberate reduction of the CBT to a range of $32-34^{\circ} \mathrm{C}$ in comatose survivors of cardiac arrest after return of spontaneous circulation (ROSC). Now, the term also includes $\mathrm{TH}$ in normothermic patients (mild HT of $33-35^{\circ} \mathrm{C}$ ) or controlled normothermia (cooling patients to $37^{\circ} \mathrm{C}$ ) in hyperthermic patients. ${ }^{[6]}$

\section{MECHANISM OF PROTECTION BY THERAPEUTIC HYPOTHERMIA}

Traditionally, HT was thought to be neuroprotective as it decreased cerebral metabolism, but alone it could not explain the non-linear protective effects so offered. Countless destructive processes such as excitotoxicty, neuroinflammatory reactions, apoptosis, free radical production, seizure activity, blood - brain barrier disruption, blood vessel leakage, cerebral thermo pooling, etc., begin in brain following neurological insult. The severity of this destructive cascade and body's response to it determines the outcome. Experimentally, $\mathrm{TH}$ has the potential to inhibit or mitigate this chain of events following the neurological insult. It influences multiple aspects of brain injury during acute, sub-acute and chronic periods, that is, weeks to months after the injury, well after cooling has stopped!

\section{Acute phase}

In the acute period, the predominant effect is on cerebral metabolism, blood flow and excitotoxicity. Cerebral oxygen and glucose consumption decreases by $5 \% /{ }^{\circ} \mathrm{C}$ fall in brain temperature. ${ }^{[7]}$ By preserving the metabolic reserves, HT prevents adversities associated with increased lactate production and subsequent acidosis during anaerobic metabolism. Probably this mechanism plays a role during global hypoxia. Under injury conditions such as ischaemic stroke, HT helps during reperfusion. At the time of reperfusion, HT blunts immediate hyperaemia and later prevents a gradual reduction in cerebral blood flow (CBF) following stroke. It also prevents the release of excitotoxic amino acids. ${ }^{[8]}$ Cooling also attenuates acute inflammatory 
processes, induction of immediate early genes, cellular stress response and induction of heat shock proteins-70. Currently, the effect of HT on microRNA (non-coding RNA) expression is under investigation. MicroRNA expression increases following ischaemia and these play a significant role in stroke pathogenesis. Cooling favourably alters the expression of microRNA. ${ }^{[9]}$

\section{Sub acute phase}

A period somewhere from 1-day to 1-week following an injury. It is actually the period when secondary insult occurs through a cascade of events. Reperfusion, inflammatory and cell death pathways are activated during this time and result in propagation of ischaemic injury. ${ }^{[10,11]}$ There is disruption of blood brain barrier, oedema formation or haemorrhage. HT offers protection by influencing the apoptotic and endogenous survival pathways, suppression of inflammation and preservation of vascular morphology. It reduces glutamate release, inflammation and free radical generation. HT may impair glutamate-mediated calcium influx or directly inhibit calcium-mediated effects of calcium/calmodulin kinase. ${ }^{[12,13]}$ The effect on ICP may be explained by stabilisation of vascular morphology and decreased oedema formation. ${ }^{[14]} \mathrm{HT}$ is shown to be protective in large models of ischaemic stroke but less commonly in models of haemorrhagic stroke. As it inhibits coagulation pathways by decreasing fibrinogen and thrombin generation, it might increase the chances of bleeding and thus correlate to poorer outcome in such cases. ${ }^{[15]}$

\section{Chronic stage}

The chronic effects are seen over a period of weeks to months, well after the cooling has stopped. HT is believed to help the injured brain to regenerate and reorganise. The exact mechanism is yet not understood but is related to protection and proliferation of stem cells by HT. It is proposed that HT influences recovery and repair mechanisms and helps in neurogenesis, gliogenesis, angiogenesis and restoration of neural circuitry. ${ }_{[12,13,16,17]}$

\section{Institution of therapeutic hypothermia}

The institution of $\mathrm{TH}$ can be divided into three main phases: Induction, maintenance and rewarming. Each one has its own risk and management issues [Table 1]. The speed and duration of cooling and rate of rewarming are the key factors in determining affectivity of $\mathrm{TH}$.

\section{Induction of cooling}

The aim of this phase is to decrease the CBT to a targeted range, as quickly as possible by available means and to deal with physiological and pathological changes associated with it. During this phase, slight overshoot is acceptable, but the temperature should not fall to $<30^{\circ} \mathrm{C} \cdot{ }^{[4,13]}$ The risk of complications such as hypotension, electrolyte disturbances and hyperglycaemia are the greatest during induction. ${ }^{[4,13,18]}$ Hypokalaemia is common due to the intracellular shift of potassium. Shivering is the major adverse effect and active intervention is required to treat it. To curtail side effects, duration of induction phase should be minimised, and more stable temperatures should be achieved quickly.

\section{The cooling equipment}

The body can lose heat by means of convection, conduction, radiation or evaporation. Consequently, HT can be attained by different devices using a combination of these principles. The rate of heat loss is dependent on the temperature gradient, conductive properties of environment and body composition. A number of devices are commercially available for achieving TH and range from the whole body to selective cerebral cooling systems [Table 2].

\section{Whole body cooling}

The methods of the whole body cooling are extensively studied and commonly used in clinical practise. The prerequisites of ideal cooling device are the rapid speed of induction, tight temperature control during maintenance and slow rewarming rates ${ }^{[4,13]}$ Grossly, the methods to attain whole body cooling can be divided into non-invasive methods and invasive methods [Table 1].

\section{Non-invasive methods}

Ice packs, water/alcohol sprays, skin exposure, etc., are cheap, readily available, non-invasive methods to achieve $\mathrm{TH}_{.}{ }^{[4,19]}$ However, these methods are cumbersome and produce erratic temperature reductions. Water or air cooling blankets with temperature feedback systems are better and have been used in large clinical trials to attain TH. ${ }^{[19-21]}$ These blankets wrap around patients body with/without adhering and automatically cool and rewarm gradually according to preset modes. They control temperature by using feedback temperature sensors from the patient's core and skin. They have been used even in awake patients. ${ }^{[21]}$ The equipment consists of a separate machine for temperature control and air/water circulated blanket. The conventional water (Blanketrol, Gaymar Meditherm, etc.))/air (Polar Air, Bair Hugger) cooling blankets induce cooling by conduction and convection, respectively. A new non-invasive temperature management system (Arctic Sun, Medivance) uses hydrogel-coated pads circulating temperature-controlled water under negative pressure and adheres to the patient's abdomen, back and thighs [Figure 1]. This is different than conventional water blankets or wraps, in which air is trapped between the cooling source and the skin and the patient is cooled by cold air (convection). The cooling rate is reported to be $1.5^{\circ} \mathrm{C} / \mathrm{h}$ or better with it. However, overall cooling and rewarming rates with blankets are less predictable and alone they take a long time to attain HT. Decreasing 
Table 1: Different phases of targeted temperature management

\begin{tabular}{|c|c|c|c|}
\hline Phase & Induction $\left(37-35^{\circ} \mathrm{C}\right)$ & Maintenance $\left(32-35^{\circ} \mathrm{C}\right)$ & Rewarming (hypothermia- $37^{\circ} \mathrm{C}$ ) \\
\hline Aim & $\begin{array}{l}\text { Maximise speed of cooling } \\
\text { for optimal neuroprotection }\end{array}$ & $\begin{array}{l}\text { Continue cooling } \\
\text { Avoid wide fluctuations } \\
\text { in temperature }\end{array}$ & $\begin{array}{l}\text { Slow rewarming } \\
\text { Active } \\
\text { Passive }\end{array}$ \\
\hline Duration & Preferably within $30 \mathrm{~min}$ & $\begin{array}{l}24 \mathrm{~h} \text {, or more depending } \\
\text { upon indication }\end{array}$ & $0.25^{\circ} \mathrm{C} / \mathrm{h}$ \\
\hline Caution & $\begin{array}{l}\text { Watch for } \\
\text { Haemodynamic instability } \\
\text { Shivering } \\
\text { Coagulation abnormalities } \\
\text { Electrolyte disturbances } \\
\text { (specially hypokalaemia) } \\
\text { Hyperglycaemia } \\
\text { Metabolic acidosis } \\
\text { Diuresis }\end{array}$ & $\begin{array}{l}\text { Thermal burns } \\
\text { Shoot down } \\
\text { Infectious complications } \\
\text { Altered drug metabolism }\end{array}$ & $\begin{array}{l}\text { Vasodilatation and haemodynamic } \\
\text { instability } \\
\text { Electrolyte disturbances } \\
\text { (especially hyperkalaemia) } \\
\text { Avoid post-rewarming fever } \\
\text { Shivering }\end{array}$ \\
\hline \multicolumn{4}{|c|}{$\begin{array}{l}\text { Ventilator care: Adjust settings according to } \mathrm{EtCO}_{2} \\
\text { Feeding requirement may be decreased } \\
\text { Maintain normoglycaemia } \\
\text { Maintain intravascular volume status } \\
\text { Drug level monitoring for important drugs } \\
\text { Standard operating protocols for infection control }\end{array}$} \\
\hline
\end{tabular}

Table 2: Methods for institution of hypothermia

\begin{tabular}{|c|c|}
\hline $\begin{array}{l}\text { Whole body } \\
\text { hypothermia }\end{array}$ & $\begin{array}{l}\text { Selective cerebral } \\
\text { hypothermia }\end{array}$ \\
\hline $\begin{array}{l}\text { Noninvasive/surface } \\
\text { cooling }\end{array}$ & Noninvasive \\
\hline $\begin{array}{l}\text { Air/water circulated } \\
\text { cooling blankets }\end{array}$ & Surface cooling \\
\hline Ice packs & Cooling helmets/caps \\
\hline Water/alcohol sprays & Fans \\
\hline Skin exposure & $\begin{array}{l}\text { Surface cooling after } \\
\text { hemicraniectomy }\end{array}$ \\
\hline \multirow[t]{2}{*}{ Immersion in cold water } & Cooling through upper airway \\
\hline & Transnasal devise \\
\hline $\begin{array}{l}\text { Invasive/core cooling } \\
\text { devices }\end{array}$ & Invasive \\
\hline Intravascular catheters & $\begin{array}{l}\text { Vascular cerebral cooling } \\
\text { methods }\end{array}$ \\
\hline $\begin{array}{l}\text { Infusion of ice-cold } \\
\text { saline }\end{array}$ & $\begin{array}{l}\text { Extraluminal anterograde } \\
\text { cerebral perfusion }\end{array}$ \\
\hline $\begin{array}{l}\text { Extracorporeal } \\
\text { circulation }\end{array}$ & $\begin{array}{l}\text { Intraluminal anterograde } \\
\text { cerebral perfusion }\end{array}$ \\
\hline \multirow[t]{2}{*}{ Antipyretics } & $\begin{array}{l}\text { Retrograde jugular venous } \\
\text { cooling }\end{array}$ \\
\hline & $\begin{array}{l}\text { Compartmental cooling } \\
\text { (epidural, subarchanoid, } \\
\text { subdural, intraventricular) }\end{array}$ \\
\hline
\end{tabular}

temperature from $37^{\circ} \mathrm{C}$ to $32^{\circ} \mathrm{C}$ may take up to $8 \mathrm{~h}$ and temperature fluctuations are common.
Invasive methods

Using intravascular cooling catheters are gaining popularity ${ }^{[22]}$ [Figure 2]. They attain $\mathrm{TH}$ rapidly, maintain a narrow temperature range and rewarm in a well-controlled manner. The device consists of a central line with two or three balloons filled with temperature controlled saline and can be inserted through subclavian, superior caval or femoral vein. ${ }^{[23,24]}$ Cooling rate is $2-2.5^{\circ} \mathrm{C} / \mathrm{h}$ and temperature can be maintained within a narrow range of $\pm 0.5^{\circ} \mathrm{C}$. Rapid (30 min) intravenous infusion of a large volume $(30 \mathrm{ml} / \mathrm{kg})$ of cold $\left(4^{\circ} \mathrm{C}\right)$ lactated Ringer's solution has also been described as an effective method of inducing $\mathrm{TH}$. In patients without cardiac shock, it can reduce CBT from $36.9^{\circ} \mathrm{C} \pm 1.9^{\circ} \mathrm{C}$ to $34.6^{\circ} \mathrm{C} \pm 1.5^{\circ} \mathrm{C}$ at $30 \mathrm{~min}$ and to $32.9^{\circ} \mathrm{C} \pm 0.9^{\circ} \mathrm{C}$ at $60 \mathrm{~min} .{ }^{[25]}$ In order to attain quick cooling, combined methods (infusion of cold saline and cooling blankets) have been described.

Despite advances in surface and core cooling devices, the average period of $2-3 \mathrm{~h}$ is still required to reach a temperature of $32-34^{\circ} \mathrm{C}$. Among water or air circulating external cooling device, gel-coated adhesive system, endovascular cooling, conventional cooling with cold saline bolus and surface cooling with ice, the intravascular cooling system attain $\mathrm{TH}$ the fastest and maintain temperature within a narrow range. These devices are also user-friendly. ${ }^{[26,27]}$ Cooling catheters change CBT and thus peripheral cooling and its consequences such as cutaneous vasoconstriction and shivering are avoided. 


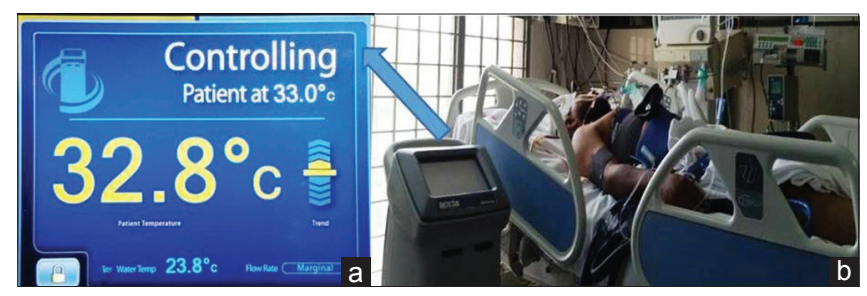

Figure 1: (a) Temperature control panel (b) Patient with surface cooling blanket in situ

\section{Antipyretics}

Heat generation in patients with hyperthermia can be reduced by antipyretics, but patients with elevated temperatures caused by impaired thermoregulation (central fever/stroke) antipyretics are often ineffective. ${ }^{[28]}$ A few preclinical have suggested the pharmacological agents such as neurotensin and its analogues, 3-iodithyronamine and hydrogen sulphide to decrease body temperature for given depth and duration. ${ }^{[29]}$

- Selective cerebral cooling is emerging to potentially overcome logistical obstacles and systemic complications of whole body HT. A number of invasive and non-invasive methods are developed to induce selective cerebral cooling [Table1]. Human research in selective HT is limited to non-invasive cooling methods

- Surface cooling of the head: Forced air-cooling helmet, cooling caps have been used in some trials to produce selective cerebral HT, but these are associated with superficial brain cooling only and regional temperature gradients are likely. ${ }^{[30,31]} \mathrm{A}$ best of $2^{\circ} \mathrm{C}$ drop in intraparenchymal temperature at a depth of $2 \mathrm{~cm}$ has been achieved. Scalp temperature does not correlate with deep brain temperature in these cases. ${ }^{[30]}$ The first cooling helmet was designed by National Aeronautics and Space Administration technology. The device has 2 components: A head/neck liner and a conditioning unit. ${ }^{[30]}$ While surface cooling of brain in adults has disadvantage of not cooling brain parenchyma uniformly, cooling caps have been successfully used for selective HT in neonates with hypoxic ischaemic encephalopathy (HIE) owing to the unique neonatal anatomy and intracranial dynamics ${ }^{[32]}$

- Selective cerebral cooling through upper airway: It is another emerging technique to provide selective cerebral HT. ${ }^{[3,34,35]}$ Transnasal evaporative cooling uses a mixture of liquid coolant and oxygen sprayed into nasopharynx through disposable nasal catheter [Figure 3]. The liquid undergoes rapid evaporation under the administration of high flow oxygen. Rhinochill (BeneChill International AG, Switzerland) is a portable device which utilises the principle of transnasal cooling. ${ }^{[33]}$ It consists of a

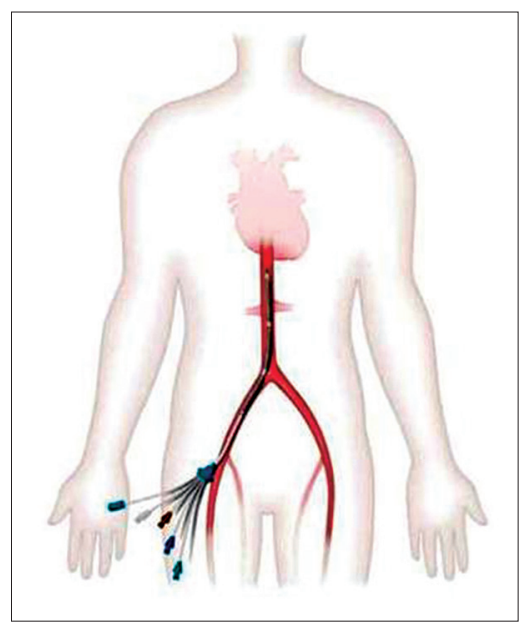

Figure 2: Endovascular cooling catheter

nasal cannula connected to battery operated control unit which controls cooling rates and switches of the device in case of high intranasal pressures. It has been successfully tested in clinical trials and results in rapid cooling of nasal passages and brain. It is especially helpful for pre-hospital and intra-arrest cooling. Device related complications are few and include periorbital emphysema, epistaxis and nasal discolouration. ${ }^{[33,34]}$ It is a safe and feasible technique and may result in significant improvement in the time required to cool the patients

- Invasive methods of cerebral cooling: Far few clinical trials are currently utilising this modality. It is an understudied approach to TH. Vascular cerebral cooling methods or conductive or convective heat transfer between various intracranial compartments can be exploited to achieve selective cerebral cooling. Injections of cooled saline or blood into an extracranial internal carotid artery (intraluminal anterograde cerebral perfusion) or retrograde venous perfusion and extraluminal cooling of the extracranial carotid artery (extraluminal anterograde cerebral perfusion) are under exploration. Transcutaneous cooling in patients with decompressive craniectomies has been used in animal models. Selective cooling can also be attained by irrigating the intracranial spaces with chilled saline. ${ }^{[35,36]}$

Among the selective cerebral cooling techniques only surface cooling methods and intranasal cooling systems have been tested in humans. Potential concerns regarding the uneven cooling of the brain is a concern with some regional methods including surface, epidural and intranasal cooling. On the other hand, endovascular cooling and extra-luminal cuffs can provide uniform cooling of the brain. The least invasive and most selective methods of TH hold the greatest promise. 


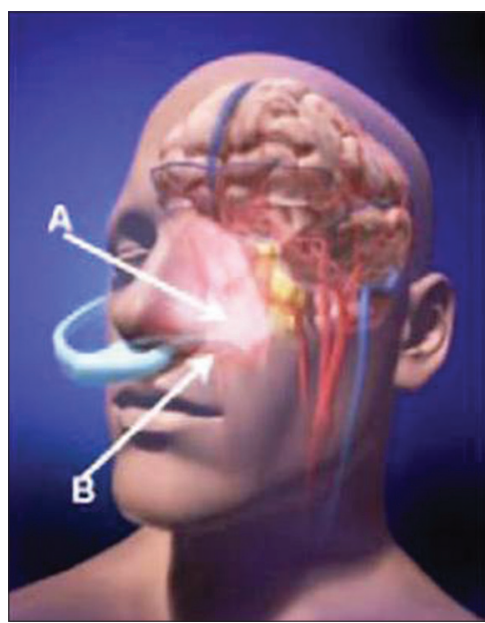

Figure 3a: Rhinochill: Transnasal evaporative cooling device, (A) coolant spray (B) nasal catheter. Reprinted with permission from BeneChill, Inc.

\section{Maintenance phase}

The aim of this phase is to maintain HT and tightly regulate the body temperature with minimal fluctuations $\left(0.2-0.5^{\circ} \mathrm{C}\right)$. It requires keeping the temperature in desired range for the appropriate length of time. There is less risk of hypotension, electrolyte disturbance or fluid shifts during this phase and once the $\mathrm{CBT}<33.5^{\circ} \mathrm{C}$, shivering decreases dramatically but complications such as pneumonia, wound infections, bed sores and coagulation abnormalities are common..$^{[4,13,18]}$ Drug dosage needs to be adjusted according to metabolism.

The timing and optimal duration of HT are not well defined. The timing of induction and duration of HT generally depend upon its indication. International Liaison Committee on Resuscitation (ILCOR) and American Heart Association (AHA) guidelines recommend patients with ROSC after out-of-hospital cardiac arrest (OHCA) should be cooled to $32-34^{\circ} \mathrm{C}$ within $2 \mathrm{~h}$ for $12-24 \mathrm{~h} .{ }^{[37,38]}$ Similarly, for neonatal $\mathrm{HIE}, \mathrm{IH}\left(33.5-34.5^{\circ} \mathrm{C}\right)$ within $6 \mathrm{~h}$ of birth for $72 \mathrm{~h}$ is recommended in infants born at $\geq 36$ weeks gestation. In trials on traumatic brain injury (TBI), TH for cerebral protection has to be started as early as possible and at least for $48 \mathrm{~h}$, while $\mathrm{TH}$ to treat refractory intracranial hypertension can be started late and can be given for longer duration ( $48 \mathrm{~h}-10$ days), as premature termination of HT can cause rebound increase in ICP. ${ }^{[37-41]}$

\section{Rewarming}

During rewarming phase, the cooled body returns to normal body temperature. Rewarming may be passive or active. Passive rewarming involves removal of the source for cooling and allowing the patient to warm on his own. Alternatively, active rewarming may be programmed into the same devices as used for cooling. Rewarming is a critical step. It should be gradual, the rate of rewarming should be $1^{\circ} \mathrm{C} / 4 \mathrm{~h}\left(0.25^{\circ} \mathrm{C} / \mathrm{h}\right)$ until the core temperature is $\geq 36^{\circ} \mathrm{C}$. Rapid rewarming

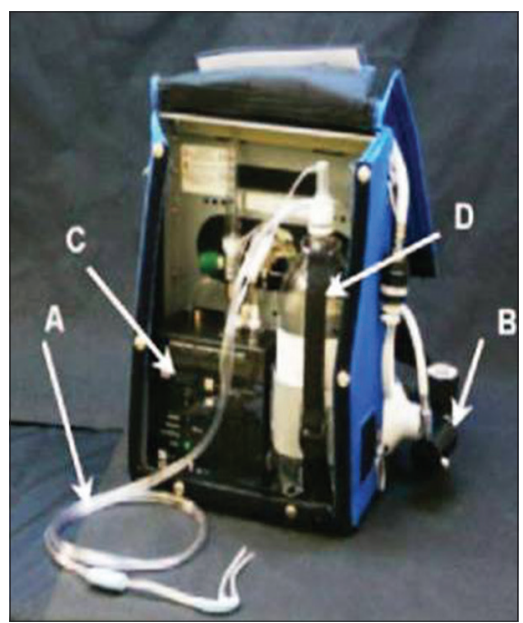

Figure 3b: (A) Nasal catheter, (B) oxygen tank, (C) control unit and (D) coolant bottle

may increase neurologic injury and not only negate protective effects of HT but also exacerbate neural pathology. Rewarming is associated with vasodilatation, hypotension, hypovolaemia, hyperkalaemia and arrhythmias. These can be mitigated by slow rewarming. These side effects should be managed effectively. Rebound intracranial hypertension is common due to rewarming induced vasodilatation. ${ }^{[4,42]}$ Watch for temperature after drop and overshoot during the early and late stages of rewarming, respectively.

\section{PHYSIOLOGICAL CHANGES OF HYPOTHERMIA}

There is a difference between pathophysiological adaptations to cooling and its side effects. While it is important to register physiological consequences of cooling, insufficient management of side effects may result in negation of protective effects. Mild HT induced a slight decrease in cardiac output, mild acidosis; the rise in lactate or amylase levels might only represents the physiological consequences of cooling and may not require treatment. However, shivering as a consequence of HT is deleterious and needs early treatment. Moderate HT is usually not associated with major complications, but deep HT adds to major morbidity. Pathophysiological changes can become major side effects with increasing depth of cooling.

- Shivering is an anticipated consequence but a major adverse effect of TH. Cooling is initially met with the resistance of counter-regulatory homeostasis mechanisms which try to maintain CBT to near normal. During use of surface cooling, there is increased sympathetic tone which leads to peripheral vasoconstriction and shivering which prevents fall in temperature. Shivering during TH induction generates significant heat and thus significantly 
reduces cooling rates. Shivering can increase oxygen consumption by $40-100 \%$ and may result in acidosis and myocardial ischaemia. It is highly undesirable, especially in patients with neurological/ post-hypoxic insult. Even mild HT can elicit a vigorous thermoregulatory defence. In healthy humans, peripheral vasoconstriction is triggered at $36.5^{\circ} \mathrm{C}$ and shivering at $35.5^{\circ} \mathrm{C}$. These thresholds are often higher than normal in brain-injured patients; therefore, these thermoregulatory defences may occur more vigorously and at higher temperatures. Younger age, male gender and lower body surface area are associated with increased shivering episodes. It is difficult to cool younger patients with higher body mass index (BMI) and robust vascular response to changes in temperature in contrast to elderly patients with a lower BMI and less effective vascular response. ${ }^{[43]}$ The bedside Shivering Assessment Scale helps in the quantification of shivering. Various methods such as deep sedation, active skin counter warming, opioids, pethidine, clonidine and magnesium have been recommended for the treatment of shivering. In awake, non-ventilated patients meperidine and buspirone have been used to control shivering in clinical trials. Therapy for shivering should suppress the central thermoregulatory reflex rather than just uncoupling of skeletal muscle response. Use of muscle relaxant stops clinical manifestations of shivering but does not mitigate the on-going cerebral and systemic stress response. Only if not controlled by sedation, muscle relaxants should be used in intensive care settings. Conversely, muscle relaxants are highly effective in controlling shivering without associated vasodilatation and hypotension. They may be superior in settings of haemodynamic instability and emergency room. Shivering is markedly depressed or absent at temperature $<33.5^{\circ} \mathrm{C}$ consequently it becomes less bothersome during the maintenance phase

- $\mathrm{CBF}$ and metabolism: The uninjured brain has closed coupling of $\mathrm{CBF}$ and $\mathrm{CMRO}_{2}$ between temperatures of $33^{\circ} \mathrm{C}$ and $35^{\circ} \mathrm{C}$. Reduction in CBF nearly parallels reductions in $\mathrm{CMRO}_{2} . \mathrm{CMRO}_{2}$ decreases by $8 \% /{ }^{\circ} \mathrm{C}$ falls in temperature. However, below $28^{\circ} \mathrm{C}$ there is uncoupling between the two and studies report the development of both ischaemic and hyperaemic states. ${ }^{[7,43]}$ The cerebral vasculature retains its responsiveness to $\mathrm{CO}_{2}$ even at reduced temperatures but in the diseased state the coupling may be disturbed. The literature demonstrates inconsistent changes in $\mathrm{CBF}$ during various diseases states such as TBI, subarachnoid haemorrhage (SAH), stroke, etc., due to loss of autoregulation. ${ }^{[44]}$ Clinically, mild HT causes confusion, dysarthria, ataxia and amnesia. Below $28^{\circ} \mathrm{C}$, there is a loss of reflexes and diminishing electroencephalogram (EEG) activity with complete EEG silence below $26^{\circ} \mathrm{C}$. In a study conducted in survivors of cardiac arrest treated with $\mathrm{HT}$, mean flow velocity in middle cerebral artery was low with normal jugular venous oxygenation. It indicates a reduction in cerebral metabolic activity as a neuroprotectant in these patients ${ }^{[45]}$

- Cardiovascular changes: TH has a variable impact on cardiovascular status. It can affect cardiac rhythm, output and peripheral vascular resistance. The magnitude of effect increases with decreasing temperature. During moderate $\mathrm{TH}$, these changes warrant close monitoring and do not require medical management in most of the cases. Cooling is initially associated with tachycardia followed by bradycardia. Tachycardia is because of initial increased myocardial oxygen demand relative to supply and TH induced increased catecholamine levels. With the further decrease in temperature decreased metabolism and depressant effect of $\mathrm{TH}$ on heart results in bradycardia. Cold induced vasoconstriction leads to increased vascular resistance and thus after load. This may result in increased vascular permeability and extravasation of fluid into extravascular circulation and manifests as increased haematocrit and blood viscosity. (4-6\%/ ${ }^{\circ} \mathrm{C}$ temperature reduction). Mild $\mathrm{TH}$ may decrease cardiac output by up to $25 \%$. Cardiac function is more suppressed with increasing levels of HT. ${ }^{[46,47]}$ Direct effect of HT on the myocardium, HT induced endogenous catecholamines or electrolyte abnormalities have a significant bearing on cardiac rhythm. Temperatures below $32^{\circ} \mathrm{C}$ have a tendency to develop atrial fibrillation and even lower temperatures are associated with the development of refractory, spontaneous ventricular fibrillation (VF). The occurrence of Osborn wave is also seen at these temperatures. Such rhythms are dangerous and warrant urgent management

Notably, the influence of $\mathrm{TH}$ on the myocardium is conflicting. Even mild $\mathrm{TH}$ reduces cardiac contractility inducing systolic and diastolic dysfunction. Coronary vasoconstriction was reported in patients with pre-existing coronary artery disease during HT. This can be taken as the theoretical risk of myocardial insult, especially in patients with cardiovascular disease. ${ }^{[47,48]}$ On the other hand, there is evidence of increased inotropy due to catecholamine release and decreased myocardial infarct size with $\mathrm{TH}$

- Coagulation abnormalities: Coagulation cascade is temperature dependent. With fall in temperature, there is increased tendency to bleed. It is due to whole host effects of HT on coagulation cascade. There is decreased the production of clotting enzymes, tissue plasminogen activator inhibitor enzyme and 
inhibition of other steps in the coagulation cascade. The platelet function and number are decreased. Throughout HT, platelets become sequestrated in the spleen and liver and re-enter the circulation after rewarming. Similar to blood gas analysis, standard blood coagulation studies are reported normal in $\mathrm{TH}$, as they are interpreted at $37^{\circ} \mathrm{C}$ in the lab. They may be prolonged if done at CBT. A meta-analysis of clinical trials of mild $\mathrm{TH}$ for traumatic head injury determined that partial thromboplastin time was slightly increased $(0.02 \mathrm{~s})$ in the $\mathrm{TH} \cdot{ }^{[4,49]}$ Despite these disturbances, the incidence of bleeding is reported to be very low, in major clinical trials including TBI. The role of $\mathrm{TH}$ in patients with trauma is controversial, as HT itself is a poor prognostic indicator in these patients. Spontaneous HT is bad as it indicates exhaustion of energy stores and, therefore, correlates more with severe injuries. The same may not hold true for TH, as it is implied in controlled manner and associated with decreased metabolic and oxygen demands in tissues and other beneficial effects. ${ }^{[49]}$ No human studies have been performed to evaluate the effect of HT in haemorrhagic shock

- Metabolic effects: TH can induce a number of metabolic effects. It shifts the oxyhaemoglobin saturation curve to the left subsequently, decreases the availability of oxygen in tissues; thus, it is not uncommon to see acidosis in hypothermic patients. HT can increase synthesis of glycerol, free fatty acids and lactate. This slight fall in $\mathrm{pH}$ may not be of clinical relevance and does not need any special treatment. ${ }^{[24]}$ Overall, metabolic rate decreases by $5-8 \% /{ }^{\circ} \mathrm{C}$ fall in body temperature. The reduction in metabolic rate leads to decreased oxygen consumption and carbon dioxide production. The production of $\mathrm{CO}_{2}$ is decreased by $30 \%$ when the core temperature is $33^{\circ} \mathrm{C}$, this requires a reduction in minute ventilation as guided by $\mathrm{EtCO}_{2}$ readings and arterial blood gas (ABG) analysis. ${ }^{[4,50-52]}$ At $37^{\circ} \mathrm{C}$, the arterial partial pressure of oxygen and carbon dioxide increase (due to increased solubility of gases following an increase in temperature) and there is a false increase in blood hydrogen ion concentration. When ABGs are corrected for temperature, the patient may have a respiratory alkalosis. Therefore, temperature corrected ABG should be analysed. Hypothermic patients have lower feeding requirements. Per se, HT or use of muscle relaxant does not call for cessation of feeding

HT leads to hypokalaemia due to the intracellular shift of potassium, especially during the induction and maintenance phases. This may require frequent monitoring and replacement of serum potassium. During rewarming potassium returns to the intravascular compartment and may produce dangerously high levels of serum potassium. Keeping serum potassium around $3.0 \mathrm{mEq}$ is desirable during this phase. Besides potassium, calcium, phosphate and magnesium levels may alter and need to be monitored.Hyperglycaemia, blood glucosevariability and insulin resistance are seen in hypothermic phase as compared to the post-rewarming normothermic conditions. ${ }^{[53]}$ It requires frequent monitoring and treatment as hyperglycaemia is an independent predictor of mortality in patients with neurological injury. Understanding the impact of $\mathrm{TH}$ on drug disposition is necessary to optimise its application and prevent drug toxicity. Cooling affects drug metabolism. This becomes, especially important during resuscitation when it may render many agents used in cardiopulmonary resuscitation ineffective or delay their response. Antiarrhythmic agents (especially amiodarone) may fail to act. The half-life of non-depolarising muscle relaxants may be prolonged. Due to depression of cytochrome p450 (CYP) related drug metabolism, commonly use antiepileptic drugs, phenytoin and fosphenytoin metabolism is depressed. TH may reduce the elimination of these drugs and lead to accumulation and toxicity. ${ }^{[54,55]}$ Monitoring plasma levels of anticonvulsants are logical

To summarise, HT may induce many metabolic changes, which are usually self-limiting but particular attention should be drawn to electrolyte disturbances, prevention of shivering and altered drug metabolism

- Infection: The suppression of inflammation by HT is like a double edged sword. On one hand inhibition of inflammatory response is beneficial for the prevention of neurological insult but at the same time it renders patient susceptible to infectious complications. It inhibits neutrophil and macrophage function, suppresses inflammatory reactions and inhibits the release of proinflammatory cytokines. ${ }^{[4,51,56]}$ HT induced insulin resistance, suppression of inflammatory response, decreased gastrointestinal motility make the patient vulnerable to pneumonia, vascular device, blood stream as well as wound-related infections. Largely, these complications are dependent on the depth and duration of HT. Shorter the duration lesser the worries! A trend towards increased the incidence of sepsis and pneumonia is seen in studies using HT. Even HACA researchers reported sepsis as the most important complication of $\mathrm{TH}$, but its occurrence was not statistically significant between normothermia and HT group (7\% vs. $13 \%) \cdot{ }^{[57,58]}$ ICTuS-L study, which used endovascular cooling along with intravenous thrombolysis for stroke also reported an increased incidence of pneumonia. ${ }^{[59]}$ Good intensive care, careful follow of protocols for 
infection control and early calculated antibiotic therapy is required to lower the risk of these complications. The use of prophylactic antibiotics is not recommended.

\section{CLINICAL APPLICATIONS OF TTM}

\section{Therapeutic hypothermia after cardiac arrest}

In 2002, two landmark prospective randomised controlled trials confirmed the efficacy of TH for cerebral protection. An 11-center European trial reported 16\% improvement in outcome in patients with witnessed arrest following ventricular tachycardia/VF, and a similar four-centre Australian study found improved outcome in $23 \%$ patients. Many other non-randomised studies have also reported improved outcomes with TH. ${ }^{[5,58,60]}$ In October 2002, the ILCOR recommended TH after cardiac arrest in unconscious adult patients with spontaneous circulation after out-of-hospital cardiac when the initial rhythm was VF, other rhythms or in-hospital cardiac arrest. ${ }^{[3]]}$ AHA recommends cooling to $32-34^{\circ} \mathrm{C}$ within $2 \mathrm{~h}$ for $12-24 \mathrm{~h}$ in comatose patients with ROSC after cardiac arrest when the initial rhythm was VF (Class I). It may be considered as a reasonable option in comatose patients with cardiac rhythm which does not respond to defibrillation or patients after in hospital cardiac arrest (Class II b). ${ }^{[38]}$ The European Resuscitation Council guidelines for resuscitation recommend $\mathrm{TH}$ for all comatose survivors of cardiac arrest regardless of initial rhythm, although the guideline acknowledges a lower level of evidence for TH in patients with a cardiac arrest from non-shockable rhythms. ${ }^{[61]}$

Though the international guidelines and reviews support the use of $\mathrm{TH}$ but questions regarding its use have been raised. Limitations of reported $\mathrm{TH}$ studies like, no strict temperature management in controls, who had an average temperature of $37.8^{\circ} \mathrm{C}$, lack of prior power calculation and a low rate of enrolment drew attention of health care professionals. The available evidence in support of HT may be considered weak, owing to bias and small sample size. ${ }^{[6,62]}$ Neilson et al. conducted a large, multicentric and randomised controlled trial which evaluated the effect of TTM at either $33^{\circ} \mathrm{C}$ or $36^{\circ} \mathrm{C}$ in 950 unconscious adults after $\mathrm{OHCA}$ of presumed cardiac cause. In their study, targeted temperature of $33^{\circ} \mathrm{C}$ had no benefit as compared to targeted temperature of $36^{\circ} \mathrm{C}$, and thus, questioned the role of cooling. This study too had some inherent flaws with its methodology and selection. ${ }^{[6,63]}$ Though these conclusions cannot be ignored but till now there is not enough evidence for discarding/favouring $\mathrm{TH}$ for strict fever management (or, worse, no temperature management). All pertinent issues need to be satisfactorily addressed. Pre-hospital and critical care management have changed during the past decade so is the associated mortality. Clinically relevant benefit of controlling the body temperature at $36^{\circ} \mathrm{C}$ or lower, instead of allowing the fever to develop in patients following resuscitation after cardiac arrest needs to be investigated in detail.

\section{Therapeutic hypothermia in traumatic brain injury}

Two possible paradigms currently tested for TBI are titrated $\mathrm{TH}$ to reduce ICP and TH for cerebral protection. Fay described the concept of cooling traumatic brains in $1945 .{ }^{[64]}$ As he used very low temperatures $\left(28^{\circ} \mathrm{C}\right)$ for long duration (4-7 days), he encountered too many side effects. The method did not gain popularity until 1990 when experimental data again showed less neurological damage with its use. Overall the results of TH in TBI are not as encouraging as in post-cardiac arrest patients, due to the obvious disparity in the patient population. In OHCA global ischaemia and reperfusion injury play a dominant role, whereas in TBI pathology is heterogenous with a variable degree of necrosis, midline shift, etc., Hence, the same results need not be expected. No high-quality evidence supports the role of this modality as a neuroprotectant and only a trend towards reduced mortality and improved outcome is seen, but a large body of evidence suggests affectivity of TH for controlling refractory intracranial hypertension. ${ }^{[41,65-67]}$ The previous studies differ in their study protocol (individualised onset/duration of cooling, the rate of rewarming), enrolling different categories of patients and diverging treatment protocols. However, from existing literature the beneficial effects of TH were significantly the greatest when it was maintained for $>48 \mathrm{~h}$, to those who have not received barbiturate therapy and had slower rewarming

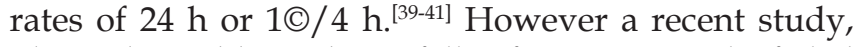
planned to address the pitfalls of previous trials, failed to demonstrate the beneficial effects of prolonged HT alongwith slow rewarming and tight hemodynamic monitoring over strict fever control in patients with TBI. ${ }^{[68]}$ Another computed tomography based Japanese study reported favourable outcome with $\mathrm{TH}$ in young patients with evacuated haematomas as compared to controlled normothermia but patients with diffuse brain injury deteriorated with $T H .{ }^{[68,69]}$ Nonetheless the current studies do not put an end to HT in TBI. The existing meta-analyses point towards the need of high quality randomised controlled trials for further demonstration of its effects and defining the depth and duration may be depending upon individual needs. ${ }^{[70]}$ Two large new trials Eurotherm 3235 trial (www.eurotherm3235trial.eu) and POLAR (http:/ / clinicaltrials.gov/ct2/show/NCT00987688) are testing the efficacy of titrated HT for raised ICP and early HT as a cerebral protectant. The studies planned to incorporate described optimised cooling protocols and to enrol specialised centres only. Eurotherm 3235 which had initially planned to recruit 600 patients has stopped 
enrollment prematurely for unknown reasons and the results are awaited. POLAR trial is currently recruiting with a focus on early cooling $(<3 \mathrm{~h})$ post-injury.

\section{Therapeutic hypothermia in ischaemic stroke}

Several experimental studies have demonstrated beneficial effects of HT in animal models of ischaemic stroke, but it is less described in haemorrhagic stroke. The institution of HT is associated with unique challenges in stroke patients. There is an innate disparity between stroke pathology and cardiac arrest. Successful resuscitation resulting in ROSC following cardiac arrest is also associated with the return of cerebral perfusion but in stroke, the affected vessel often remains occluded for a long time in the absence of reperfusion therapies. Most of the stroke patients are awake and un-intubated. Thus, discomfort associated with deliberate cooling is high and the management of shivering difficult. Pharmacological or mechanical approaches are required for early recanalisation. Recombinant tissue plasminogen activator (rt-PA) is currently the only beneficial proven therapy for stroke. The safety of combining HT with rt-PA is not well proven. Both fibrinolytic therapy and HT are associated with haemorrhagic complications and the efficacy of fibrinolytic agents is temperature dependent, lower temperatures associated with decreased activity. ${ }^{[71,72]}$ The rt-PA was effective in improving recanalisation, and cooling can reduce infarct size, but the combination of the two did not clearly show synergy. Due to late presentation of patients with stroke, the therapeutic window for the institution of TH needs to be determined. ${ }^{[73]}$ The application of combination therapy such as using HT to expand the temporal therapeutic window of rt-PA should be explored.

The ICTuS-L study is a recent randomised multicentre trial of HT and rt-PA in acute stroke patients. ${ }^{[59]}$ Here, 58 patients were randomised, 28 to $\mathrm{HT}$ at $33^{\circ} \mathrm{C}$ for $24 \mathrm{~h}$ and 30 to normothermia. In the HT group, 24 were also given rt-PA. Cooling was well tolerated in this study and did not affect the occurrence or severity of brain haemorrhage in patients given rt-PA. There were no differences in 90-day outcomes, although the study was not powered to determine efficacy.

\section{Therapeutic hypothermia in subarachnoid haemorrhage}

The largest randomised trial of intraoperative HT for aneurysm surgery (Intraoperative Hypothermia for Aneurysm Surgery Trial) applied HT in 1001 patients with good-grade SAH. In this trial, no difference in neurological outcome was seen between hypothermic and normothermic groups, 3 months post-surgery. ${ }^{[74-76]}$ However, these results may not be extrapolated to patients with poor-grade SAH. The most important and potentially treatable complication of SAH is intracranial hypertension and delayed cerebral ischaemia leading to progressive cerebral infarction. The strength of $\mathrm{TH}$ in SAH is thought to be directed towards ischaemia rather than haemorrhage itself. TH has shown to attenuate the degree of cerebral vasospasm up to 14 days after SAH possibly by regulating the levels of ET-1 and NO. Good outcome following the application of prolonged HT within $24 \mathrm{~h}$ in poor-grade SAH is reported in few case series. Similarly, HT either during delayed aneurysm clipping or in cases with vasospasm refractory to hyperdynamic and endovascular therapy has shown to help..$^{[77-79]}$ Available data suggests that HT may improve outcome in a carefully selected subgroup of SAH patients. The patients developing intracranial hypertension and/or symptomatic vasospasm refractory to conventional treatment may benefit from it. More evidence on this subject is required to draw fruitful conclusions.

\section{Hypothermia in perinatal hypoxic-ischaemic encephalopathy}

Even with major advances in monitoring and knowledge of perinatal medicine, HIE is one of the significant causes of mortality and long-term morbidity. The pioneer studies described the feasibility of TH in neonates with HIE more than a decade ago. ${ }^{[80]}$ Data from large randomised clinical trials indicate that cooling is an effective therapy for HIE. Both whole body cooling and selective head cooling have been successfully implemented since then.

Randomised controlled trials showing decreased death or disability in neonates treated within $48 \mathrm{~h}$ of birth with the whole body HT have been published. ${ }^{[11-84]}$ Meta-analysis of these trials suggests positive effect of TH. Although the trials had some differences in the method of cooling and selection of subjects, but infants enrolled were at least 35 weeks gestation at birth; randomised within $6 \mathrm{~h}$ of birth, cooled to a target temperature of $33.5-34.5^{\circ} \mathrm{C}$ for $72 \mathrm{~h}$, followed by slow rewarming $\left(0.5^{\circ} \mathrm{C} / \mathrm{h}\right)$. The primary outcome measure was the combined rate of death or disability, assessed at 18-22 months of age. Adverse effects of TH in the target temperature range were infrequent. The most common adverse effects were sinus bradycardia and prolongation of QT interval on electrocardiogram, both of which are physiologic responses to HT. Reddening or hardening of the skin (systemic HT) and on the scalp (selective head cooling) and subcutaneous fat necrosis occurred rarely. The reported rates of coagulopathy, sepsis and pneumonia were same in treated and control infants. When published studies were aggregated in a meta-analysis, the adverse effects of HT included an increase in sinus bradycardia and a significant increase in thrombocytopenia (platelet count $150,000 / \mathrm{mm}^{3}$ ). The adverse effect of pyrexia on 
neurologic outcome among infants allocated to standard care was obvious. ${ }^{[84,85]}$ ACLS guidelines recommend $\mathrm{TH}$ in infants born at $\geq 36$ weeks of gestation with evolving moderate to severe hypoxic-ischaemic encephalopathy. ${ }^{[39]}$

Still there are unanswered questions regarding the use of this modality in neonates. Optimal timing for initiation of cooling and the depth and duration of therapy needs further evaluation. As cooling and its management are preferably done in higher centres and many neonates are unable to reach higher centres within $6 \mathrm{~h}$ so clinical trials designed to assess the efficacy of initiating cooling between 6 and $12 \mathrm{~h}$ of age are required. There is uncertainty regarding the safety and efficacy of initiating cooling before transfer to a centre offering TH. Safety and efficacy of cooling treatment of encephalopathic infants born at $<35$ weeks of gestational age are currently lacking.

\section{Other applications}

Clinical evidence has demonstrated TTM to be effective in treating refractory status epilepticus. Cortical spreading depression (CSD) has been described as one of the causes in the development of ischaemia in TBI and stroke and $\mathrm{TH}$ has been shown to suppress CSD. Other applications include use in experimental and clinical spinal cord injury, myocardial infarction and cardiogenic shock. It is also used for the management of hepatic failure.

\section{Controlled normothermia}

To avoid the negative effects of fever and $\mathrm{TH}$, controlled normothermia was introduced. Fever is an independent predictor of poor outcome for several neurological diseases. ${ }^{[86]}$ Symptomatic fever control is becoming the popular goal of therapy in neurocritical illness. Controlled normothermia is bringing down core temperature in patients with fever and maintaining temperature within a range of $36.0-37.5^{\circ} \mathrm{C}$ with potentially deleterious effects such as shivering, being controlled or suppressed. Most of the HT trials conducted in past failed to effectively manage body temperature in controls. Controls had fever episodes and were not actually normothermic throughout the study time. Satisfactory normothermia cannot be achieved in a fever by drug treatment alone. ${ }^{[87]}$ Reasonable treatment of fever must be combined with general measures of infection control and supportive treatment protocols. Routine antipyretics have a limited role in controlling neurological fever. The average decrease in CBT with the use of acetaminophen is only about $0.3-0.4^{\circ} \mathrm{C}$. Surface, endovascular cooling and new pharmacological methods are being increasingly used for the treatment of fever. The methods used to treat fever depend upon the availability, expertise and relevant resources. Though there is no superiority of one method over other and a combination of these techniques make a reasonable option. In few trials, endovascular methods of controlling temperature have been found to be superior to conventional temperature control methods (combination of nonsteroidal anti-inflammatory drugs and surface cooling) in patients with the severe cerebrovascular disease. ${ }^{[88]}$ Controlled HT has its own set of limitations, important being shivering and effect on immune response. During fever, hypothalamus resets the CBT to a higher target value and body heat preservation methods are maximally activated to achieve this new set point. For this reason, it is not easy to attain controlled normothermia.

\section{Future directions}

TTM can be a boon for treating millions of life worldwide. Currently, the strongest evidence for TTM in adults is following cardiac arrest, neonatal HIE and ICP control. Controlled normothermia in neurocritical care population is rapidly gaining recognition. Data on disease specific therapeutic markers, therapeutic depth and duration and prognostication of this modality is limited. The optimal speed and time to initiate; duration of cooling and rewarming rates in different pathologies need to be more defined. ${ }^{[43]}$ Modern Intensive Care Unit protocols for HT follow a 'one temperature fits all' mentality. Newer studies are correlating temperature management and brain metabolism or surrogate markers may answer important questions pertaining to this modality in neurological insult. Overall in experienced hands the technique is safe without major morbidity but a potential to improve outcome.

\section{Financial support and sponsorship Nil.}

\section{Conflicts of interest}

Authors are investigators of EUROTHERM3235 trial.

\section{REFERENCES}

1. Brown DJ, Brugger H, Boyd J, Paal P. Accidental hypothermia. N Engl J Med 2012;367:1930-8.

2. Stocchetti N, Zanier ER. Brain temperature. In: Le-Roux PD, Levine JM, Kofte WA, editors. Monitoring in Neurocritical Care. Philadelphia: Elsevier Saunders; 2013.

3. Childs C, Lunn KW. Clinical review: Brain-body temperature differences in adults with severe traumatic brain injury. Crit Care 2013;17:222.

4. Polderman KH, Herold I. Therapeutic hypothermia and controlled normothermia in the intensive care unit: Practical considerations, side effects, and cooling methods. Crit Care Med 2009;37:1101-20.

5. Logue ES, McMichael MJ, Callaway CW. Comparison of the effects of hypothermia at 33 degrees $C$ or 35 degrees $C$ after cardiac arrest in rats. Acad Emerg Med 2007;14:293-300.

6. Nielsen N, Wetterslev J, Cronberg T, Erlinge D, Gasche Y, Hassager $\mathrm{C}$, et al. Targeted temperature management at $33^{\circ} \mathrm{C}$ versus $36^{\circ} \mathrm{C}$ after cardiac arrest. $\mathrm{N}$ Engl J Med 2013;369:2197-206. 
7. Yenari M, Wijman C, Steinberg G. Effects of hypothermia on cerebral metabolism, blood flow and autoregulation. In: Mayer S, Sessler D, editors. Hypothermia in Neurocritical Care. New York: Marcel Dekker, Inc.; 2004. p. 141-78.

8. Hemmen TM, Lyden PD. New approaches to clinical trials in neuroprotection: Introduction. Induced hypothermia for acute stroke. Stroke 2007;38:794-9.

9. Truettner JS, Alonso OF, Bramlett HM, Dietrich WD. Therapeutic hypothermia alters microRNA responses to traumatic brain injury in rats. J Cereb Blood Flow Metab 2011;31:1897-907.

10. Liu L, Kim JY, Koike MA, Yoon YJ, Tang XN, Ma H, et al. FasL shedding is reduced by hypothermia in experimental stroke. J Neurochem 2008;106:541-50.

11. Bramlett HM, Dietrich WD. Pathophysiology of cerebral ischemia and brain trauma: Similarities and differences. J Cereb Blood Flow Metab 2004;24:133-50.

12. Yenari MA, Han HS. Neuroprotective mechanisms of hypothermia in brain ischaemia. Nat Rev Neurosci 2012;13:267-78.

13. Polderman KH. Mechanisms of action, physiological effects, and complications of hypothermia. Crit Care Med 2009;37 7 Suppl: S186-202.

14. Kawanishi M,Kawai N,Nakamura T,Luo C,Tamiya T,Nagao S. Effect of delayed mild brain hypothermia on edema formation after intracerebral hemorrhage in rats. J Stroke Cerebrovasc Dis 2008; 17:187-95.

15. MacLellan CL, Davies LM, Fingas MS, Colbourne F. The influence of hypothermia on outcome after intracerebral hemorrhage in rats. Stroke 2006;37:1266-70.

16. Saito K, Fukuda N, Matsumoto $\mathrm{T}$, Iribe $\mathrm{Y}$, Tsunemi A, Kazama $\mathrm{T}$, et al. Moderate low temperature preserves the stemness of neural stem cells and suppresses apoptosis of the cells via activation of the cold-inducible RNA binding protein. Brain Res 2010;1358:20-9.

17. Silasi G, Colbourne F. Therapeutic hypothermia influences cell genesis and survival in the rat hippocampus following global ischemia. J Cereb Blood Flow Metab 2011;31:1725-35.

18. Schubert A. Side effects of mild hypothermia. J Neurosurg Anesthesiol 1995;7:139-47.

19. Bernard SA, Gray TW, Buist MD, Jones BM, Silvester W, Gutteridge $\mathrm{G}$, et al. Treatment of comatose survivors of out-of-hospital cardiac arrest with induced hypothermia. N Engl J Med 2002;346:557-63.

20. Hypothermia after Cardiac Arrest Study Group. Mild therapeutic hypothermia to improve the neurologic outcome after cardiac arrest. N Engl J Med 2002;346:549-56.

21. Kammersgaard LP, Rasmussen BH, Jørgensen HS, Reith J, Weber U, Olsen TS. Feasibility and safety of inducing modest hypothermia in awake patients with acute stroke through surface cooling: A case-control study: The Copenhagen Stroke Study. Stroke 2000;31:2251-6.

22. Finley Caulfield A, Rachabattula S, Eyngorn I, Hamilton SA, Kalimuthu R, Hsia AW, et al. A comparison of cooling techniques to treat cardiac arrest patients with hypothermia. Stroke Res Treat 2011;2011:690506.

23. Holzer M, Müllner M, Sterz F, Robak O, Kliegel A, Losert H, et al. Efficacy and safety of endovascular cooling after cardiac arrest: Cohort study and Bayesian approach. Stroke 2006;37:1792-7.

24. Bernard S. Therapeutic hypothermia after cardiac arrest. Neurol Clin 2006;24:61-71.

25. Polderman KH, Rijnsburger ER, Peerdeman SM, Girbes AR. Induction of hypothermia in patients with various types of neurologic injury with use of large volumes of ice-cold intravenous fluid. Crit Care Med 2005;33:2744-51.

26. Hoedemaekers CW,Ezzahti M,Gerritsen A,vanderHoeven JG. Comparison of cooling methods to induce and maintain normo- and hypothermia in intensive care unit patients: A prospective intervention study. Crit Care 2007;11:R91.

27. Våga A, Busch M, Karlsen TE, Nilsen OB, Søreide E. A pilot study of key nursing aspects with different cooling methods and devices in the ICU. Resuscitation 2008;76:25-30.

28. Kasner SE, Wein T, Piriyawat P, Villar-Cordova CE, Chalela JA, Krieger DW, et al. Acetaminophen for altering body temperature in acute stroke: A randomized clinical trial. Stroke 2002;33:130-4.

29. Lee JH, Wei L, Gu X, Wei Z, Dix TA, Yu SP. Therapeutic effects of pharmacologically induced hypothermia against traumatic brain injury in mice. J Neurotrauma 2014;31:1417-30.

30. Wang H, Olivero W, Lanzino G, Elkins W, Rose J, Honings D, et al. Rapid and selective cerebral hypothermia achieved using a cooling helmet. J Neurosurg 2004;100:272-7.

31. Laptook AR, Shalak L, Corbett RJ. Differences in brain temperature and cerebral blood flow during selective head versus whole-body cooling. Pediatrics 2001;108:1103-10.

32. Gluckman PD, Wyatt JS, Azzopardi D, Ballard R, Edwards AD, Ferriero DM, et al. Selective head cooling with mild systemic hypothermia after neonatal encephalopathy: Multicentre randomised trial. Lancet 2005;365:663-70.

33. Castrén M, Nordberg P, Svensson L, Taccone F, Vincent JL, Desruelles D, et al. Intra-arrest transnasal evaporative cooling: A randomized, prehospital, multicenter study (PRINCE: Pre-ROSC IntraNasal Cooling Effectiveness). Circulation 2010;122:729-36.

34. Poli S, Purrucker J, Priglinger M, Sykora M, Diedler J, Rupp A, et al. Safety evaluation of nasopharyngeal cooling (RhinoChill ${ }^{\circledR}$ ) in stroke patients: An observational study. Neurocrit Care 2014;20:98-105.

35. Straus D, Prasad V, Munoz L. Selective therapeutic hypothermia: A review of invasive and noninvasive techniques. Arq Neuropsiquiatr 2011;69:981-7.

36. Wei G, Hartings JA, Yang X, Tortella FC, Lu XC. Extraluminal cooling of bilateral common carotid arteries as a method to achieve selective brain cooling for neuroprotection. J Neurotrauma 2008;25:549-59.

37. Nolan JP, Morley PT,Vanden Hoek TL, Hickey RW, Kloeck WG, Billi J, et al. Therapeutic hypothermia after cardiac arrest: An advisory statement by the advanced life support task force of the International Liaison Committee on Resuscitation. Circulation 2003;108:118-21.

38. Peberdy MA, Callaway CW, Neumar RW, Geocadin RG, Zimmerman JL, Donnino $\mathrm{M}$, et al. Part 9: Post-cardiac arrest care: 2010 American Heart Association guidelines for cardiopulmonary resuscitation and emergency cardiovascular care. Circulation 2010;122 18 Suppl 3:S768-86.

39. Kattwinkel J, Perlman JM, Aziz K, Colby C, Fairchild K, Gallagher J, et al. Part 15: Neonatal resuscitation: 2010 American Heart Association Guidelines for cardiopulmonary resuscitation and emergency cardiovascular care. Circulation 2010;122 18 Suppl 3:S909-19.

40. Brain Trauma Foundation; American Association of Neurological Surgeons; Joint Section on Neurotrauma and Critical Care, AANS/CNS: Guidelines or management of severe head injury. J Neurotrauma 2007;24(suppl):S1-S106.

41. Peterson K, Carson S, Carney N. Hypothermia treatment for traumatic brain injury: A systematic review and meta-analysis. J Neurotrauma 2008;25:62-71.

42. Povlishock JT, Wei EP. Posthypothermic rewarming considerations following traumatic brain injury. J Neurotrauma 2009;26:333-40.

43. Corry JJ. Use of hypothermia in the intensive care unit. World J Crit Care Med 2012;1:106-22.

44. Keller E, Steiner T, Fandino J, Schwab S, Hacke W. Changes in cerebral blood flow and oxygen metabolism during moderate hypothermia in patients with severe middle cerebral artery 
infarction. Neurosurg Focus 2000;8:e4.

45. Bisschops LL, van der Hoeven JG, Hoedemaekers CW. Effects of prolonged mild hypothermia on cerebral blood flow after cardiac arrest. Crit Care Med 2012;40:2362-7.

46. Frank SM, Satitpunwaycha P, Bruce SR, Herscovitch P, Goldstein DS. Increased myocardial perfusion and sympathoadrenal activation during mild core hypothermia in awake humans. Clin Sci (Lond) 2003;104:503-8.

47. Kanemoto S, Matsubara M, Noma M, Leshnower BG, Parish LM, Jackson BM, et al. Mild hypothermia to limit myocardial ischemia-reperfusion injury: Importance of timing. Ann Thorac Surg 2009;87:157-63.

48. Hale SL, Kloner RA. Mild hypothermia as a cardioprotective approach for acute myocardial infarction: Laboratory to clinical application. J Cardiovasc Pharmacol Ther 2011;16:131-9.

49. Kheirbek T, Kochanek AR, Alam HB. Hypothermia in bleeding trauma: A friend or a foe? Scand J Trauma Resusc Emerg Med 2009;17:65.

50. Soleimanpour H, Rahmani F, Golzari SE, Safari S. Main complications of mild induced hypothermia after cardiac arrest: A review article. J Cardiovasc Thorac Res 2014;6:1-8.

51. Bernard SA, Buist $M$. Induced hypothermia in critical care medicine: A review. Crit Care Med 2003;31:2041-51.

52. Tripathy S,Mahapatra AK. Targeted temperature management in brain protection: An evidence-based review. Indian J Anaesth 2015;59:9-14.

53. Cueni-Villoz N, Devigili A, Delodder F, Cianferoni S, Feihl F, Rossetti AO, et al. Increased blood glucose variability during therapeutic hypothermia and outcome after cardiac arrest. Crit Care Med 2011;39:2225-31.

54. Tortorici MA,Kochanek PM,Poloyac SM.Effectsofhypothermia on drug disposition, metabolism, and response: A focus of hypothermia-mediated alterations on the cytochrome P450 enzyme system. Crit Care Med 2007;35:2196-204.

55. Empey PE, de Mendizabal NV, Bell MJ, Bies RR, Anderson KB, Kochanek PM, et al. Therapeutic hypothermia decreases phenytoin elimination in children with traumatic brain injury. Crit Care Med 2013;41:2379-87.

56. Kimura A, Sakurada S, Ohkuni H, Todome Y, Kurata K. Moderate hypothermia delays proinflammatory cytokine production of human peripheral blood mononuclear cells. Crit Care Med 2002;30:1499-502.

57. Hypothermia after Cardiac Arrest Study Group. Mild therapeutic hypothermia to improve the neurologic outcome after cardiac arrest. N Engl J Med 2002;346:549-56.

58. Wang XP, Lin QM,Zhao S, Lin SR,Chen F. Therapeuticbenefits of mild hypothermia in patients successfully resuscitated from cardiac arrest: A meta-analysis. World J Emerg Med 2013;4:260-5.

59. Hemmen TM, Raman R, Guluma KZ, Meyer BC, Gomes JA, Cruz-Flores $\mathrm{S}$, et al. Intravenous thrombolysis plus hypothermia for acute treatment of ischemic stroke (ICTuS-L): Final results. Stroke 2010;41:2265-70.

60. van der Wal G, Brinkman S, Bisschops LL, Hoedemaekers CW, van der Hoeven JG, de Lange DW, et al. Influence of mild therapeutic hypothermia after cardiac arrest on hospital mortality. Crit Care Med 2011;39:84-8.

61. Deakin CD, Nolan JP, Soar J, Sunde K, Koster RW, Smith GB, et al. European Resuscitation Council Guidelines for Resuscitation 2010 Section 4. Adult advanced life support. Resuscitation 2010;81:1305-52.

62. Arrich J,Holzer M,Havel C,MüllnerM,Herkner H.Hypothermia for neuroprotection in adults after cardiopulmonary resuscitation. Cochrane Database Syst Rev 2012;9:CD004128.

63. Polderman KH, Varon J. We should not abandon therapeutic cooling after cardiac arrest. Crit Care 2014;18:130.

64. Fay $T$. Observations on generalised refrigeration in cases of severe cerebral trauma. Assoc Res Nerv Ment Dis Proc
1945;24:611-9.

65. Clifton GL, Valadka A, Zygun D, Coffey CS, Drever P, Fourwinds $\mathrm{S}$, et al. Very early hypothermia induction in patients with severe brain injury (the National Acute Brain Injury Study: Hypothermia II): A randomised trial. Lancet Neurol 2011;10:131-9.

66. Clifton GL, Miller ER, Choi SC, Levin HS, McCauley S, Smith KR Jr, et al. Lack of effect of induction of hypothermia after acute brain injury. N Engl J Med 2001;344:556-63.

67. Sydenham E, Roberts I,Alderson P.Hypothermiafortraumatic head injury. Cochrane Database Syst Rev 2009; Issue 2. Art. No.: CD001048. DOI: 10.1002/14651858.

68. Maekawa T, Yamashita S, Nagao S, Hayashi N, Ohashi Y; Brain-Hypothermia Study Group. Prolonged mild therapeutic hypothermia versus fever control with tight hemodynamic monitoring and slow rewarming in patients with severe traumatic brain injury: A randomized controlled trial. J Neurotrauma 2015;32:422-9.

69. Suehiro E, Koizumi H, Fujisawa H,Fujita M, Kaneko T, Oda Y, et al. Diverse effects of hypothermia therapy in patients with severe traumatic brain injury based on the computed tomography classification of the traumatic coma data bank. J Neurotrauma 2015;32:353-8.

70. Mass A, Stocchetti N. Hypothermia and complexity of trials in patients with TBI. Lancet 2011;10:111-3.

71. Lyden PD, Krieger D, Yenari M, Dietrich WD. Therapeutic hypothermia for acute stroke. Int J Stroke 2006;1:9-19.

72. Tang XN, Liu L, Yenari MA. Combination therapy with hypothermia for treatment of cerebral ischemia. J Neurotrauma 2009;26:325-31.

73. Krieger DW, Yenari MA. Therapeutic hypothermia for acute ischemic stroke: What do laboratory studies teach us? Stroke 2004;35:1482-9.

74. Hindman BJ, Todd MM, Gelb AW, Loftus CM, Craen RA, Schubert A, et al. Mild hypothermia as a protective therapy during intracranial aneurysm surgery: A randomized prospective pilot trial. Neurosurgery 1999;44:23-32.

75. Todd MM, Hindman BJ, Clarke WR, Torner JC; Intraoperative Hypothermia for Aneurysm Surgery Trial (IHAST) Investigators. Mild intraoperative hypothermia during surgery for intracranial aneurysm. N Engl J Med 2005;352:135-45.

76. Anderson SW, Todd MM, Hindman BJ, Clarke WR, Torner JC, Tranel D, et al. Effects of intraoperative hypothermia on neuropsychological outcomes after intracranial aneurysm surgery. Ann Neurol 2006;60:518-27.

77. Anei R, Sakai H, Iihara K, Nagata I. Effectiveness of brain hypothermia treatment in patients with severe subarachnoid hemorrhage: Comparisons at a single facility. Neurol Med Chir (Tokyo) 2010;50:879-83.

78. Nagao S, Irie K, Kawai N, Nakamura $\mathrm{T}$, Kunishio $\mathrm{K}$ Matsumoto $Y$. The use of mild hypothermia for patients with severe vasospasm: A preliminary report. J Clin Neurosci 2003;10:208-12.

79. Seule M,Keller E. Hypothermia after aneurysmal subarachnoid hemorrhage. Crit Care 2012;16 Suppl 2:A16.

80. Azzopardi D, Robertson NJ, Cowan FM, Rutherford MA, Rampling M, Edwards AD. Pilot study of treatment with whole body hypothermia for neonatal encephalopathy. Pediatrics 2000;106:684-94.

81. Gluckman PD, Wyatt JS, Azzopardi D, Ballard R, Edwards AD, Ferriero DM, et al. Selective head cooling with mild systemic hypothermia after neonatal encephalopathy: Multicentre randomised trial. Lancet 2005;365:663-70.

82. Shankaran S, Laptook AR, Ehrenkranz RA, Tyson JE, McDonald SA, Donovan EF, et al. Whole-body hypothermia for neonates with hypoxic-ischemic encephalopathy. $\mathrm{N}$ Engl J Med 2005;353:1574-84.

83. Azzopardi D,Brocklehurst P,Edwards D, Halliday H,Levene M, 
Thoresen M, et al. The TOBY Study. Whole body hypothermia for the treatment of perinatal asphyxial encephalopathy: A randomised controlled trial. BMC Pediatr 2008;8:17.

84. Edwards AD, Brocklehurst P, Gunn AJ, Halliday H,Juszczak E, Levene $\mathrm{M}$, et al. Neurological outcomes at 18 months of age after moderate hypothermia for perinatal hypoxic ischaemic encephalopathy: Synthesis and meta-analysis of trial data. BMJ 2010;340:c363.

85. Jacobs SE, Berg $M$, Hunt $R$, Tarnow-Mordi WO, Inder TE, Davis PG. Cooling for newborns with hypoxic ischaemic encephalopathy. Cochrane Database Syst Rev 2013;1:CD003311.
86. Greer DM, Funk SE, Reaven NL, Ouzounelli M, Uman GC. Impact of fever on outcome in patients with stroke and neurologic injury: A comprehensive meta-analysis. Stroke 2008;39:3029-35.

87. Den Hertog HM, van der Worp HB, Tseng MC, Dippel DW. Cooling therapy for acute stroke. Cochrane Database Syst Rev 2009;Issue 1. Art. No.: CD001247. DOI: 10.1002/14651858.

88. Broessner G, Beer R, Lackner P, Helbok R, Fischer M, Pfausler B, et al.Prophylactic, endovascularly based, long-term normothermia in ICU patients with severe cerebrovascular disease: Bicenter prospective, randomized trial. Stroke 2009;40:e657-65. 